\title{
USE OF MULTIPLE METHODS: AN EXAMINATION OF CONSTRAINTS EFFECTING ETHNIC MINORITY VISITOR USE OF NATIONAL PARKS AND MANAGEMENT IMPLICATIONS
}

\author{
Nina S. Roberts \\ San Francisco State University
}

\section{Donald A. Rodriguez \\ California State University, Channel Islands}

Understanding outdoor recreation participation and national park visitation by members of ethnic minority groups has been a particular focus of outdoor recreation researchers for the past twenty years. Attracting ethnic minorities, and understanding their recreation needs and interests, demands a multi-faceted approach and sustained commitment not only by the U.S. National Park Service (NPS) but by other resource management agencies as well.

The world has changed profoundly since the first national parks were created and the national park "idea" continues to provide benefits of fundamental importance to this country. Yet, despite the inspiration provided and uplifting of our spirits, there are unmet recreational needs and opportunities unfulfilled. Furthermore, as the complexion of the nation changes, our experiences as a people 


\section{Ethnic Studies Review Volume 31}

are also undeniably becoming more diverse. The future of the NPS may well be tied to the changing demographics of the country, in general, and the American West in particular. Empirical research on outdoor recreation experiences of ethnic minorities and national parks is on the rise yet still remains largely unexplored.

According to Machlis and Field (2000), "while the 'average visitor' has never existed, the diversity of visitors is likely to increase further in the next decade" (p. 7). This will serve to widen the gap among the visiting public regarding interpretation, communication, and management direction. We recognize that the ethnic diversity of visitors is likely to increase, bringing new recreation styles, uses, and needs to national parks and their bordering gateway communities. Furthermore, investigating the attitudes, perceptions and outdoor recreation experiences of ethnic minorities and national parks has received little research attention from an empirical standpoint (e.g., Floyd, 1999; Hutchison, 2000; Sasidharan, 2002; Solop, Hagen, \& Ostergren, D., 2003).

Rocky Mountain National Park (RMNP) in Colorado, receives over three million visitors annually. Although various diversity initiatives have achieved some notable successes (e.g., outreach to Denver-based youth groups), ethnic minorities and individuals from low income backgrounds are still underrepresented in outdoor recreation participation at RMNP. This study explores why this might be the case.

\section{Terms and Nomenclature}

Racial terms are sometimes problematic because of their imprecise social, cultural and geographic meaning. Language among racial and ethnic groups evolves over time and terms change with societal events and influences. The term "African American" has been in common usage in the parks and recreation literature. Also popular in this field is use of the term "Black". This article respectfully uses both of these terms interchangeably to be more inclusive, to not assume the meaning or connotation associated with each, and because respondents in this study selfidentified using either one term or the other. Second, the generic term "Hispanic" was officially created by the U.S. Census Bureau 
in 1970 to designate people of Spanish origin; this is considered "inaccurate, incorrect, and often offensive" as used for all Spanishspeaking people or Latinos (Comas-Díaz, 2001).

Despite classification by the U.S. Census Bureau, individuals whose heritage is from Central, South or Latin America, and even Caribbean groups such as Cubans, Dominicans, and Puerto Ricans, have "Latino" as their least common denominator and, according to Comas-Díaz (2001) is the preferred name of these populations. As a result of the predominant Mexican/Mexican American (e.g., Chicano) community in Colorado this paper uses the term "Latino(s)" from this point forward in general content, not including Census Bureau references that still includes use of "Hispanic" (U.S. Census, 2004).

\section{Review of literature}

Race, ethnicity, and culture

There are several reviews of literature on the topic of ethnicity/ race in parks and recreation (e.g., Allison, 1988; Johnson, Bowker, English \& Worthen, 1997; Floyd, 1999; Gómez, 2007; Gómez, 2003; Gramann \& Allison, 1999; Hutchison, 2000; Sasidharan, 2002; Shinew, et al., 2006), and outdoor recreation specific experiences (Rodriguez \& Roberts, 2002). The concepts of race, ethnicity, and culture have come to the forefront of social science and natural resource management over the last several years to address growing issues of diversity of outdoor recreation users of public lands. Debates about the role of ethnicity and culture have sparked a movement towards research that is directly applicable to social issues relating to natural resource management. For instance, topics such as attitudes, preferences, participation patterns and styles, constraints, "meaning" (e.g., nature, experiences), and general recreation behavior associated with diverse racial/ethnic groups have seen a large rise in funding for both research and specialized training for public land agency managers.

Understanding race, ethnicity and constraints relating to outdoor recreation and park use

In general, issues surrounding race or ethnicity and constraints to recreation participation have not been given the attention they 


\section{Ethnic Studies Review Volume 31}

deserve (Jackson, 2005; Phillip, 1995; Shinew, Floyd \& Parry 2004; Rodriguez \& Roberts, 2002). Studies that do exist suggest that typical constraint models need refinement, given their lack of consideration for racial issues. According to a variety of scholars in the field of parks and recreation, further studies are needed to examine how race or ethnicity and constraints to recreation participation as well as park use are truly interrelated (Arnold \& Shinew, 1998; Gobster, 1993; Parry, Shinew \& Arnold, 2001; Phillip, 1995; Shores, Scott, \& Floyd, 2007).

In his comprehensive review on race/ethnicity and use of the National Park System, Floyd (1999) reported different ethnic groups' exhibit various rates of visiting national parks as well as recreation activity participation. Groups studied show variation in both style of use and overall experiences. For example, from years of documented studies, Whites are known to visit national parks at higher proportions than any other racial group. Furthermore, while similarities and differences are reported among all users (e.g., Latino and Asian American appear more similar in activity participation; Blacks less likely to venture out into the wilderness), ethnic minority visitors are more likely to report experiences with discrimination (perceived or real) during their visits than Whites (including higher reports by Blacks than any other group). Following this structured and influential review related to racial and ethnic minority use of national parks, Floyd's emphasis for future research needs suggested consideration for "the role of discrimination in minority decisions regarding park use has not received adequate research attention" (Floyd, 1999, p. 18).

Recent literature addressing the topic of national park visitation and constraints to use includes a national study commissioned by the NPS Social Science Program with Northern Arizona University. Solop, et al. (2003), conducted a survey of 3515 households in 2000 of which $32 \%$ of respondents reported visiting a national park within the last two years. They found that Hispanic Americans and African Americans were more likely than Whites to identify the overall costs, lack of information and travel distance as constraints to park visitation. African Americans were more than three times as likely as Whites to believe that park employees gave poor service to visitors, and that parks were uncomfortable places to be for 
people similar to themselves. Additionally, Hispanic Americans were concerned about making a camping reservation too far in advance and were twice as likely then Whites to be concerned about personal safety.

Johnson, Bowker, and Cordell (2001) examined the specific role of race, gender, and urban residence and found of those three factors, gender was a significant predictor of constraints for the participants. Women identified concerns about personal safety, inadequate facilities and information, insufficient funds, and outdoor pests. While race was not a significant predictor, however, African Americans were much more likely than whites to feel inhibited by personal safety concerns. Urban residence did not appear to be an important factor to outdoor recreation participation according to this study.

Shinew et al., (2004) found African Americans have become more accustomed to negotiating constraints, and thus have developed strategies of resistance to empower themselves in life (in general) and in desires for recreation, specifically. Their study also indicated that African Americans report a lower preference for nature based activities than Caucasians, which is consistent with much of the literature.

Floyd (2001) explored several hypotheses used toexplain primary issues of access and use including the construct of discrimination which is segmented in two key components. First, interpersonal discrimination relates to "actions carried out by members of dominant racial or ethnic groups that have differential and negative impacts on members of minority groups" (Feagin, 1991 in Floyd 2001, p. 47). Second, institutional discrimination "focuses on the 'behavior' of organizations, bureaucracies, or corporate entities. This hypothesis assumes discriminatory practices are embedded in the structure, policies, or procedures of organizations" (Floyd, 2001, p. 49). He concludes by reiterating the NPS mandate to serve the American public and the rationale to find common ground with the people it serves.

Finally, Roberts (2007) engaged nearly 100 ethnic minorities around the Bay Area regarding use or non-use of the Golden Gate National Recreation Area (GGNRA). Using a focus group technique, self-identified Blacks, Latinos and Asians were interviewed about 


\section{Ethnic Studies Review Volume 31}

both onsite experiences with visiting GGNRA as well as exploring constraints if they have never been. First, from a values standpoint, findings revealed that the majority of the individuals interviewed care deeply about parks and natural resource issues. Many people, however, expressed not knowing how these resources are managed or by whom. This reflects a communications gap between certain ethnic groups and the GGNRA. Second, regarding constraints, the following five broad categories emerged from the data across ethnic groups: Access issues (transportation, associated costs, safety. and fear); communication (language issues, signage, printed brochures/ materials not always available or known that they exist); lack of knowledge, experience, and awareness (where to go or what to do); representation (lack of ethnic minorities on staff/workforce diversity, lack of awareness of, or questioning, recruitment and hiring practices), and discrimination, cultural differences, and perceived prejudice.

\section{Rocky Mountain National Park and Study Purpose}

Rocky Mountain National Park (RMNP) was established in 1915 and consists of more than 265 thousand acres of which the majority is considered wilderness. It represents a high mountainous environment (up to $14,000 \mathrm{ft}$ in elevation at its highest peak) with over three million visitors each year. Home to diverse plant and wildlife species, the park also prides itself on its interpretive programs designed to educate the general public about the rugged yet fragile ecosystems.

The purpose of this study was to obtain information about recreation participation and non-participation at Rocky Mountain National Park (RMNP) from African American and Latino residents of the State of Colorado, as well as a national panel of minority natural resource professionals. This occurred through an examination of various constraints as well as effect of perceived discrimination impacting ethnic minority visitation or non-use of national parks, in general. A supplemental aspect was to explore general outdoor recreation patterns, understand the "meaning of nature", and attitudes towards visitor services. This study involved a mixed-method approach and was guided by four primary research questions: 


\section{Roberts-Use of Multiple Methods}

1. What do ethnic minority resource professionals believe are the most salient issues relating to national park visitation of under-represented groups?

2. What types of experiences and activities are desired from travel to RMNP by African Americans and Latinos, residing along the Colorado Front Range?

3. How do African American and Latino visitors and non-visitors compare regarding reported constraints to park visitation?

4. What influence do ethnicity, culture, gender, and class have on constraints to participation?

\section{Conceptual Framework}

Constraints theory is the primary framework guiding this study and the construct of discrimination was explored as a valuable factor providing necessary support. Constraints theory is based on much of the work by Jackson and colleagues and is noted in one aspect of their research:

"...there exists a cohesive body of knowledge that has developed rationally and progressively over the last two to three decades. The conceptual dimensions of the phenomenon have been outlined, theory-based models havebeen constructed, and there has been some empirical investigation and verification of propositions and hypotheses arising from these models" (Jackson \& Scott, 1999, p. 311).

Constraints research in the field of parks and recreation was originally conceptualized in the 1980 s as a mechanism for better understanding barriers to activity participation (Jackson, 2005; Samdahl \& Jekubovich, 1997). Crawford, Jackson, and Godbey (1991) identified three primary types of barriers: intrapersonal, interpersonal, and structural. According to the authors intrapersonal barriers reflect psychological states and individual attributes such as stress, anxiety, depression, and socialization into (or away from) specific activities. Interpersonal barriers involve the interactions and relationships between individuals such as the inability to locate a suitable partner for a backpacking trip. Structural barriers are factors which intervene between preferences or choices and actual participation. Examples of structural barriers might include having adequate financial resources, available time, suitable climate, or even institutional considerations. 


\section{Ethnic Studies Review Volume 31}

From a management perspective, research to date has only just begun to provide sufficient information as to what specific strategies might minimize constraints to participation (i.e., within managers' power and jurisdiction) (Walker, Jackson \& Deng, 2005). Not only has there been a lack of ethnic diversity in natural resource management personnel, there has been a proportionate lack of interest in understanding the influence cultural diversity exerts in resource values and use (Schelhas, 2002). Scholars must extend the application of constraint theory to incorporate the perspectives of non-traditional visitors if park leadership is to understand those factors that limit their participation.

Results of the current study move beyond the boundaries of the traditional constraints theory, hierarchical notions, or even constraints negotiation to reach a deeper understanding in relationship to different ethnic groups. Constraints relating to parks use can, indeed, help us understand differences in outdoor recreation behavior between subgroups of our society and broader contextual variables that shape people's choices of what to do during their leisure time.

Realizing that constraints theories and hypothetical frameworks proposed thus far do not apply to everyone, this study investigates the intrapersonal, interpersonal and, to a lesser degree, structural constraints related to park visitation experienced by African Americans and Latinos in Colorado. Also, elements of perceived discrimination embedded in institutional practices and experiences of park visitors and minority resource professionals, were also considered as integral to this discussion of constraints. That is, it is essential to drive home the point that "perceived discrimination", an important intrapersonal constraint, has often been overlooked in past constraints research.

In the parks and recreation literature, the concept of perceived discrimination is defined as that which exerts a negative affect on visitation among racial and ethnic minorities whether real or alleged (Floyd, 1999). Two concepts connected with this approach of interest to this present study are displacement and avoidance. That is, ethnicity and race may be associated with "displacement" where a recreation area can develop a specific identity or reputation as a location 
providing certain types of experiences cultural groups find desirable or undesirable. Avoidance suggests minority groups may avoid certain areas where they expect to experience discrimination (or some other undesirable behavior or condition) either from other visitors or park staff (Williams \& Carr, 1993; Gramann 1991 cited in Gramann, 1996; Gramann \& Floyd 1991 cited in Floyd, 1999). However, these concepts have rarely been linked to factors relating to ethnicity and culture in connection with inter- and intrapersonal constraints.

Additionally, the responses to discrimination (i.e., how this alters recreation behavior) have received less attention than the range of discrimination such as avoidance, exclusion, physical threats, or blatant attacks. Gramann (1996) and Floyd (1999) suggest that avoidance and displacement may be important variables in understanding the behavioral consequences of discrimination. Finally, understanding the type of constraints experienced by ethnic minority visitors and non-visitors to Rocky Mountain National Park may shed new light on the role of discrimination as a constraint to park visitation.

\section{Methodology}

This study explored constraints experienced by African American and Latino visitors and non-visitors to RMNP in particular, and to U.S. National Parks in general. Data were collected in two distinct phases that included a Delphi technique and focus groups. A total of 70 African Americans and Latinos participated in both phases of the study.

First developed in the 1950s, the Delphi has been one of the better known methods of studying current trends and forecasting the future (Baughman, 1985; Weatherman \& Swenson, 1974). In its simplest form, the Delphi technique is "a group of related procedures for eliciting and refining the opinions of a group of people" (Weatherman \& Swenson, 1974, p. 97). More specifically, the Delphi involves inviting a panel of experts in a particular field to respond to a questionnaire and make independent, knowledgeable judgments about the assigned topic or issue under investigation.

The few scholars that have used this technique in forestry planning, forest service recreation resource management and 


\section{Ethnic Studies Review Volume 31}

environmental assessment, for instance, have substantiated the Delphi process as less expensive, more reliable, more versatile compared to other methods of soliciting group consensus, and a highly effective means of augmenting decision-making with useful information (e.g., Anderson \& Schneider, 1993; Baughman, 1985; Clark \& Stankey, 1991; Richey, Mar, \& Horner, 1985).

While reaching consensus is the goal of this method, subsequent studies using this procedure support numerous iterations as long as the research team deems necessary (Anderson \& Schneider, 1993; Baughman, 1985). In other words, a Delphi process could consist of two or three rounds without any real loss of information and the overall investigation could involve relatively minimal time for both the expert panel and research team members.

The Expert Panel: This phase involved professionals in the field of parks and recreation who attended a forum called "Black, Brown, and Green-Seeking Common Ground: A Dialogue by Latino and African American Leaders on Natural Resource Issues." This event was sponsored by the National Hispanic Environmental Council and the RoundTable Associates in October 1999.

The nature of this conference included a uniform mix of participants related to age, years in the field, and management and leadership experience. Furthermore, participants ("key informants") worked in six different settings adding to the strength of knowledge and customs of this group. That is, federal, state, municipal/city agency, nonprofit, private/for profit, and education institutions were represented. While none of the literature reviewed lent strong support to a particular panel size, according to Weatherman and Swenson (1974), the Delphi technique is typically used with groups of fifty or fewer participants. A "large scale Delphi" (IsD) consists of 100 or more. Central to the process is that invited candidates meet established criteria and those who agreed to participate were accepted.

All 40 attendees at this meeting were formally invited to participate in this study representing the target minority groups thereby providing an ideal panel to query. Based on the composition of this group and familiarity with Rocky Mountain National Park, it was agreed that this collection of experts would benefit the project as a whole by seeking their knowledge, perceptions, and experiences of ethnic minority 
recreation in parks and natural areas from a broad perspective.

Study Procedures: This Delphi process consisted of three iterations: The initial open-ended questionnaire administration and two iterations of the results review. The series of questionnaires were distributed by electronic mail as preferred by the participants. This increased the momentum of transmitting information as well as efficiency of summarizing responses for each subsequent round. In the first round questionnaire, a simple open-ended question was used to elicit a list of outdoor recreation constraints as perceived by these ethnic minority leaders working in the field: "From your point of view, what are the barriers and constraints experienced by ethnic minorities that limit their visitation to national parks?"

Six focus groups were conducted, following the Delphi, with fifty-three individuals from African American and Latino backgrounds. These individuals participated in their respective racial groups together in order to maintain group cohesion and an enhanced level of comfort with potentially being more candid with their responses. A snowball sampling technique occurred with trusted and respected community leaders to ultimately form each focus group process that included between 9 and 15 participants. There were 34 females and 19 males ranging in age from 18 to 63. Spanish language translators were present for two of the Latino focus groups. A series of fifteen semi-structured questions set the foundation for the process. Table 1 depicts the primary categories of questions asked during the interviews. All focus group interviews were taped, transcribed, and coded for content.

Table 1. Categories guiding focus group questions for semi-structured interviews

$\checkmark$ Activity enjoyment (e.g., what type of recreation do you pursue?)

$\checkmark$ Value of nature / natural environment

$\checkmark$ Comfort level (e.g., nature in general or RMNP specifically)

$\checkmark$ Constraints to visiting RMNP

$\checkmark$ Experiences with discrimination (perceived or real)

Workforce diversity (e.g., "does it matter to you?")

Marketing/Public Relations - What works best? 


\section{Ethnic Studies Review Volume 31}

\section{Data Analysis}

Delphi: The invitation was sent to 40 participants ("key informants") and twenty-five responded with an affirmative "yes" to participate in this phase while only four gave a definitive "no." To maximize involvement, the remaining 11 were included in correspondence unless they requested otherwise. After two follow-up reminders 14 (56\%) responded to the initial question. The second questionnaire was sent and after two reminders, 17 $(68 \%)$ completed round two. It was determined that a third and final round would occur. Important to note about this final round is that it took place right after the "9-11" tragedy in America resulting in a reduction of participants for obvious reasons. Two reminders were again sent resulting in 14 completed questionnaires (i.e., $56 \%$ response rate). Basic demographics for all respondents who contributed comments to the procedure are shown in Table 2.

Table 2. Basic demographics of panelists contributing to the procedure

\begin{tabular}{|l|l|}
\hline Gender: & $\begin{array}{l}\text { Position level: } \\
\text { Upper management/Executive }=9 \\
\text { Middle } \mathrm{mgmt}=6 \\
\text { Field Staff }=1 \\
\text { Unknown }=1\end{array}$ \\
\hline & Type of agency where employed: \\
Self-ascribed race: & Federal $=6$ \\
Hispanic $=7$ & State $=1$ \\
Black/African American $=7$ & Municipal/City Agency $=2$ \\
Bi-racial* $=2$ & Non-Profit $=4$ \\
White $=1$ & Private/For Profit $=2$ \\
& Education institution $=2$ \\
& (university; middle school) \\
\hline
\end{tabular}

* White/Native American

Hispanic/Native American

Responses to the initial open-ended question were first used to elicit a list of outdoor recreation constraints: "From your point of view, what are the barriers and constraints experienced by ethnic minorities that limit their visitation to national parks?" Using a content analysis procedure, responses were organized and compiled 
based on keyword associations and patterns that emerged from the aggregated data then ultimately grouped into ten categories. Based on the frequency of responses, these categories were considered the most prevalent ones for further analysis. Validity was achieved as each member of the research team completed this task on separate occasions, compared outcomes, and generally agreed on the meaning of the responses to formulate logical items used for the final list.

This resulting list of constraints was sent to participants a second time to determine the degree of agreement around items listed. In this second questionnaire, salience was an essential aspect to obtain for the analysis. Participants were asked to rank these ten categories according to what they believed were the most notable barriers/constraints to minority use and participation of national parks. The items were ranked from 1 to 10 , with " 1 " being the most important reason related to the greatest depth of meaning or leading deterrent to participation and " 10 " being the lowest in not as strong a reason in this list of constraints. Additionally, we encouraged participants to provide feedback regarding whether they agreed or disagreed with the items as stated. For instance, of interest was whether these experts believed the items reflected their perceptions of what the constraints actually were. Responses were then computed by obtaining a mean rank for each category positioned by each person. Three classifications were developed based on the rank order of panelist responses (i.e., high, medium, and low salience). Because of the wide variety of opinions, experiences, and knowledge, the research team did not provide panelists with further rankings for the third round rather included these groups as "clusters" that resulted from calculating their ranks of each of the ten items.

Focus Groups: A constant comparative technique (Glaser \& Strauss, 1967) and analytic induction were used as tools for analysis. The data were analyzed in two primary ways: Interviews were first coded using descriptive codes derived from the interview questions. Second, interviews were then coded by emerging patterns, themes and categories as part of the movement from data description to conceptual clarification. Coding for content and emerging 


\section{Ethnic Studies Review Volume 31}

themes occurred via eight major topics: 1) Value of nature/natural environment; 2) Familiarity with NPS and specific travel/visits to RMNP; 3) Activity interests (e.g., included probes about ranger-led programs and/or visitor centers); 4) Barriers/constraints to visiting RMNP; 5) Experiences of "fear" or concerns either while at the park or as possible constraints to visiting (includes discrimination as an inquiring factor); 6) Comfort level (e.g., nature in general or RMNP in particular); 7) Marketing issues; and 8) Workforce diversity from a very broad stance (e.g., "does it matter to you?"). Based on the focus group structure for this study, no effort was made to tease out the relative effects of gender, income, or marital status.

Finally, use of mixed-methods with minority users and nonusers allowed the researchers to shed light on perspectives of constraints to participation, in general, as well as perceptions of discrimination in particular. Results of each method were compared, the researchers checked for consistency of findings across data sources, and common threads were noted and recorded.

\section{Results and Findings}

This primary focus of this study was to gather information about the perceptions and experiences of African Americans and Latinos pertaining to Rocky Mountain National Park. Understanding constraints and potential discrimination factors of these minority groups were at the core of this project.

First, corroborating with the literature (Dwyer, 1994; Jones, 1998; Parker \& McDonough, 1999; Hutchison, 2000; Roberts, 2007; Rodriguez \& Roberts, 2002), respondents in this study expressed high regard for outdoor recreation, strong values for parks, and genuine concern for the natural environment. There seems to be a persistent myth that ethnic minorities do not value the outdoors or related recreational activities (e.g., "we just don't do that"). Instead, balance in nature and connecting with the "Creator" through special places are hallmarks of both African American and Latino lifestyles.

In general, nearly two-thirds of all respondents indicated understanding the values their culture places on the natural environment is very important. Similarly, more than half indicated 


\section{Roberts-Use of Multiple Methods}

some positive level of interest in "learning about protecting nature" as an activity of interest in the next five years.

Second, these facets notwithstanding, constraints to participating in outdoor activities at RMNP still exist and perceptions of discrimination for not visiting the park were apparent but acts of discrimination were never blatant. More than eighteen years ago, West (1989) was the first to employ constructs of uncomfortable/ unwelcome into his work in order to conceptualize variables related to cultural constraints. These variables were precursors to the present study when constraints were considered. Furthermore, West (1989) was the first to raise the issue of perceived geographic distance (subjective and objective) as a possible factor influencing park usage. This was an essential component in determining how much "distance" is truly a phenomenon of the cultural map based on the location of RMNP for minority residents of Colorado.

Results, as documented in these two phases, will focus on cumulative findings that are the result of a distillation of content analytical procedures. That is, qualitatively, content analysis, de-contextualization and re-contextualization (reduction and interpretation of data) occurred. Subsequently, by converging the cumulative results of these two data sets, the greatest overall judgments of the study are provided.

\section{Phase I: Ten primary factors were distilled from the Delphi (Table 3).}

Table 3. Categories developed and total rank per category for Delphi Results

\section{Constraint Category ${ }^{2}$}

Total Rank

1. Socialization as a child into outdoor recreation

and exploring natural areas

2. Lack of marketing efforts towards minority communities .......57

3. Culture of the National Park Service ..................................65

4. Education about the outdoors..................................... 70

5. Marginalized nature of ethnic minority groups ...................86

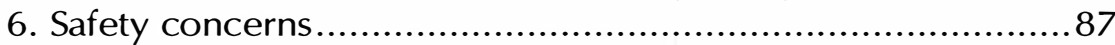




\section{Ethnic Studies Review Volume 31}

7. Lack of a range of opportunities for minority groups ............97

8. Perception among minority groups ................................. 97

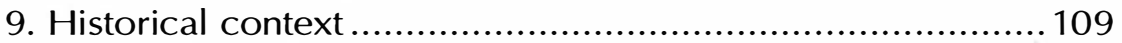

10. Perceptions by whites that perceive these areas are "their place" ............................................................ 11

1 From round one 15 categories were initially identified and further analysis revealed five of the categories were similar enough to other categories to collapse the list into the top 10. 2 The order of importance has an inverse relationship to the mean rank: The lowest total rank is equivalent to the most important, highest rated constraint by this panel. Perceived discrimination factors were found to be embedded in comments pertaining to lack of marketing, culture of the NPS, marginalization, safety concerns, historical context, and perceptions by whites.

Examples of interpersonal constraints resulting from this analysis of responses by the expert panel include socialization (e.g., cultural connections with others to the outdoors limited) as an example of an overall constraint for this level. Second, on an intrapersonal level it was noted that exposure to parks and natural areas during childhood is a constraint to participation as adults. As a structural constraint, the culture of the National Park Service was a primary category that surfaced as a variable of interest. Examples of messages include lack of marketing efforts towards ethnic minorities as a concern, lack of a range of opportunities for this population was brought up as an observation, and lack of ethnic minorities on staff was an issue for some respondents. Lack of education about the outdoors was also a strong response by Delphi participants. 
Roberts-Use of Multiple Methods

\section{Phase II: Table 4 reflects the key themes and their related meanings as distilled by the researchers from focus groups.}

Table 4. Constraint Themes Resulting from African American and Latino Focus Groups

\begin{tabular}{|c|c|}
\hline Theme & Meaning \\
\hline $\begin{array}{l}\text { Preference/convenience of city/ } \\
\text { local parks }\end{array}$ & $\begin{array}{l}\text { Proximity to residence and/or } \\
\text { neighborhood }\end{array}$ \\
\hline Safety issues & $\begin{array}{l}\text { Physical and/or emotional; fear; } \\
\text { discomfort }\end{array}$ \\
\hline Costs and transportation & Marginalized nature of ethnic minorities \\
\hline Marketing and public relations & $\begin{array}{l}\text { Lack of attention/consideration for } \\
\text { minorities }\end{array}$ \\
\hline Perceived discrimination & $\begin{array}{l}\text { Someone exerting a negative effect on } \\
\text { visitation }\end{array}$ \\
\hline Socialization and exposure & $\begin{array}{l}\text { Parental/family involvement as youth; } \\
\text { culture }\end{array}$ \\
\hline Lack of knowledge \& awareness & $\begin{array}{l}\text { Benefits of participation; opportunities; } \\
\text { facilities }\end{array}$ \\
\hline $\begin{array}{l}\text { Historical context \& } \\
\text { perspectives }\end{array}$ & $\begin{array}{l}\text { Effects of slavery; migrant labor; share } \\
\text { croppers }\end{array}$ \\
\hline Trust issues ("social permission") & $\begin{array}{l}\text { Peer pressure; lack of role models; } \\
\text { disbelief }\end{array}$ \\
\hline
\end{tabular}

As noted in Table 3, many responses were similar to the results of the Delphi phase with the differences in the following areas: Intrapersonal constraints were noted as physical and emotional safety issues and fear while examples of constraints on an interpersonal level related to peer pressure, and lack of role models. Two structural constraints that were divergent to the panel of experts, perceived discrimination and historical contexts (e.g., effects of slavery and impact on contemporary leisure choices) were strong themes converging for focus group respondents.

Key findings from both phases: Taken together both methodological procedures $(n=70$ participants) point toward gender issues of high consideration in the reporting of constraints, and that respondent perceptions and experiences also cut across ethnicity and culture in varying degrees. While respondents in both phases mentioned varying socio-economic circumstances as constraints for some individuals, this variable was not specifically measured. Hence, data analyses reveal that gender was a primary 


\section{Ethnic Studies Review Volume 31}

demographic variable that may be more likely to influence what level or impact of consideration and salience the constraints have on individual perceptions and experiences with constraints to participation in outdoor recreation in natural areas in general or RMNP in particular.

Respondents in both phases indicated gender roles seem to play a large part in the opinions or way of thinking about the outdoors and natural resources. Examples include involvement because of husband or male companion, concerns about daughters being outdoors, issues with hair and activities where women/girls would get dirty, and when participating women - in some cases would remain "close to camp to watch the children and/or cook the meals".

While "lack of transportation" (or reliable transportation) was a concern for people at some level, overall results also show that decisions to visit RMNP move beyond merely focusing on this issue (e.g., marginality) to the influence of cultural values and perceived discrimination regarding perceptions of the park or desire to visit. Consequently, the common ground in the results of both methods includes the following constraint dimensions.

1) Intrapersonal: Lack of knowledge of the benefits of visiting or participation regarding programs/activities (e.g., "what to do there") and exposure as a child.

2) Interpersonal: Personal discomfort/safety issues and socialization (e.g., "not part of my culture").

3) Structural: Culture of the National Park Service (including lack of ethnic minorities in the workforce), perceived discrimination, and historical contexts. 
Roberts-Use of Multiple Methods

Figure 1. The company of common factors among both methods ${ }^{1}$

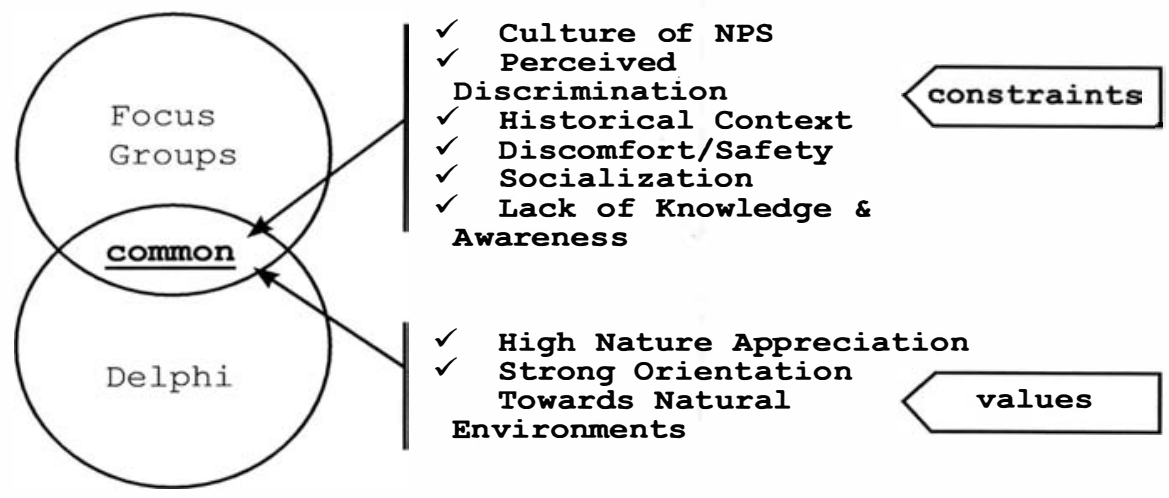

1 Total participants; $n=70$

There were numerous responses to questions asked about discomfort and safety that surfaced in the focus group interviews and Delphi process. These variables related to aspects of fear of the unknown, do not like bugs/wildlife, heard stories that "bad things have happened to people like me" at RMNP or other similar natural areas. Two other comments made were: "I personally have no inferior thoughts on race issues, I just enjoy" and "Not a people issue, it's an uninvited animal safety issue." On the other hand, two comments offer a contrasting perspective for why they would not feel safe at RMNP regarding other people as constraints:

I would use the term 'yokels' or 'rednecks' - other categories are prejudiced, white middle-class to bigoted upper 'Anglo' class people.

[African American male]

The rangers or other personnel assume I am there to cause trouble.

[Latina female]

There was an overall concurrence among respondents in both phases that lack of knowledge and awareness was a strong consideration for under-representation in park visitation. For 


\section{Ethnic Studies Review Volume 31}

example, individuals noted they did not know anything about RMNP, or what the opportunities are, for why they would want to visit. How would I benefit? was a common question asked by many focus group respondents. Comments made by key informants in the Delphi phase regarding the publics' lack of information were consistent with focus group participants such as lack of knowledge regarding the national park system and mission as well as the role of ethnic minorities in shaping the NPS over the years (e.g., early African American rangers, Buffalo Soldiers, Smoke Jumpers). Additionally, remarks included uncertainty about the opportunities at RMNP and other national parks as an issue.

The theme of socialization issues in both phases varied from childhood upbringing to trust issues and the need for "social permission" from members of one's community and peers. Individuals in both the focus groups and Delphi agreed that early childhood exposure to national parks is central to educating children about the parks and developing an interest and support in the future. This may or may not occur in family settings. Outdoor recreation is clearly very much a cultural norm; part of what this study revealed is the preference for activities in neighborhood parks and/or local city parks for many reasons, some which have previously been mentioned.

The structural constraint dimension relating to culture of the NPS is a universal characteristic among respondents, to some degree, in both phases. Again, lack of marketing to ethnic minority communities, not enough opportunities of interest, inadequate facilities, and the perception that RMNP is intended for middleto-upper class white people include other examples of how this variable was measured.

Finally, as a supplemental area of inquiry, having more ethnic minorities working in the park, also an element assessed in the NPS culture, was a fairly balanced concern among respondents in both phases (e.g., approximately half of all individuals in each phase expressed this as a concern). Comments related to the need to educate the park staff regarding reasons for promoting ethnic diversity in employment and professional development. Having

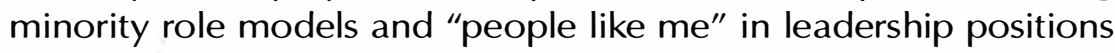


was expressed as being very important to individuals in this study.

Similarly, the small proportion of Blacks and Latinos from the study sample that have visited RMNP had experiences across the spectrum from exceptional and "loved it" to discomfort and fear. The representation of intra- and interpersonal constraints were somewhat balanced overall.

\section{Discussion}

Using a mixed method approach provided a certain amount of evidence that some levels of discrimination existed in this study setting. Responses by both the panel of experts from across the country and minorities in the sample residing within a 60-mile radius of RMNP, offered a consistent explication regarding how discrimination affects decisions to visit this park. The attributes of avoidance and displacement, for example, were powerful indicators of non-visitation. It can be argued that attitudes of non-visitors, regarding their perceptions of visitor's ethnicity, can influence the shaping of interpersonal constraints regarding a desire to venture out to RMNP or not. Convincing evidence for this phenomenon was obtained by the fact study participants (in both phases) note that minorities will typically not travel to locations they perceive they may not be welcome or comfortable and moving from one park area to another, due to fear of other dominant white visitors behavior towards them or their family (or friends), is prohibitive to a positive experience. Findings have shed some light on unique constraints associated with cultural experiences of some Blacks and Latinos relating to park use.

The findings of this study, for both phases collectively, can contribute to our understanding of outdoor recreation constraints specific to African American and Latino communities. On the basis of this analysis from combining the data, several pertinent aspects supporting both discrimination and constraints theory should be discussed. First, race, ethnicity, and culture (independently or some combination thereof) are factors that study participants could articulate when they discussed their attitudes or experiences relating to Rocky Mountain National Park and other similar natural areas. 


\section{Ethnic Studies Review Volume 31}

Despite this aspect, important to note is that culture was a larger factor for some ethnic minorities than for others. Latinos noted that language issues and national origin, for instance, heavily influenced one's perception, and this was not a concern with Blacks or mixed ethnic/racial groups. On the other hand, more Blacks had a slightly stronger attachment to their culture based on their sense of identity, connections to cultural norms and traditions, and ethnic interaction preferences.

The structural constraint dimension relating to culture of the NPS is a universal characteristic among respondents to some degree in both phases. Lack of ethnic minorities on staff, not enough opportunities of interest, inadequate facilities, and the perception that RMNP is intended for middle-to upper class white people are examples highlighted in the results. One key informant stated:

"I believe the fairly rigid National Park Service definition of what a national park service visitor should do and how the visitor should do it is, after the obvious economic barrier by lower income families, is the biggest constraint to ethnic/ cultural diversity among national park visitors."

Likewise, one Latina woman speaking in her native Spanish stated, "I think color or race is not as important or where you are from, the important thing is that the park staff-including police rangers-need to be educated on how to relate better with people from different cultures."

One common denominator is for NPS managers to recognize the interconnectedness of their decisions and management actions and the fact that the difficult questions they face are ultimately questions of value judgments and the desire for social change, not supplying political rhetoric. Social science is a key input to decisionmaking, but this represents only part of the answer. Hence, results show the need to sort out economic-based questions and issues from those which are social and/or political in nature. And, most important, there is a need to strike a balance between them.

A significant result from both phases is that while ethnicity/race should not be overlooked, this is not the most salient factor that 
constrains the experiences and perceptions of participants in this study. When comparing groups for significant differences, gender and income have a stronger relationship to constraints as reflected in the focus groups primarily and, to a lesser degree of salience, with the Delphi panel of expert as well. Results corroborated findings from previous studies on gender where, for example, females report higher constraint scores than males (e.g., Arnold \& Shinew, 1998; Henderson \& Bialeschki, 1993; Jackson \& Henderson, 1995; Virden \& Walker, 1999).

Additionally, social class may have a more powerful influence on participation and nonparticipation than what may be truly understood or perceived (Hartmann \& Overdevest, 1989; Hutchison, 2000; Philipp, 1995). As noted by Crawford, et al. (1991), constraints experiences may be more related to a hierarchy of social privilege. Nonetheless, results of this study also indicate neither gender-specific nor income factors alone are adequate explanations of these differentials but these two sets of variables influence the determination of ethnic-racial differences in park visitation and constraints to participation/visitation.

The challenges in addressing the constraints facing African Americans and Latinos along the Front Range of Coloradoregarding outdoor recreation-go beyond ethnicity/race and must be considered in terms of social and economic terms rather than exclusively ethnic or cultural ones. With the changing demographics comes a changing "ethnic economy." We must better understand the implications. Although "times have changed," we cannot ignore the importance of economic factors in contributing to both constraint and discrimination theories. That is, while based on the nature of emerging themes in this study, it was discovered that outdoor recreational decisions of both Blacks and Latinos depend largely on their economic resources as well as their cultural backgrounds to navigate the national park setting. As noted by Pickering (2000b) each society (or community) has its own understanding of the "economic behaviors and values" for that community. The need for sensitivity to cultural conceptions of economy is paramount in any field of study and outdoor recreation and resource management is no exception. 


\section{Ethnic Studies Review Volume 31}

The concept of life experiences within the urban/city boundaries as a major part of the "comfort zone" for Black respondents surfaced as a common thread for focus group participants while economic factors associated with outdoor recreation provides an example of differences within the Black community (e.g., cost an issue for some people not others). Furthermore, cultural stereotypes can be broken from learning about differences between Blacks and Latinos such as comprehending family structures, language barriers, and different perceptions of discrimination.

Inquiring about ones perception and/or experience with discrimination in the outdoors can be a powerful and loaded assertion. Historically, for example, there were rules and regulations excluding Blacks from participation in public parks and beaches. Although the Civil Rights and other similar movements have helped diminish these prohibitions, lingering effects have impacted people's attitudes and perceptions in varying ways. "The persistence of discrimination, even among those who are educationally most similar, implies that discrimination-at least as a residual measurecannot be ignored (or declared overestimated) and may have historically been as central to explanations of socioeconomic status gaps as education itself" (Marks, 1993, p. 167).

Results show noticeable support for discrimination as a theoretical basis. In the focus group interviews no one reported experiencing any overt or blatant discrimination. All experiences and perceptions on this topic revolved around discomfort with other visitors (e.g., examples provided about white visitors), displacement (e.g., moving from one location to another to avoid being on the receiving end of potential discriminatory acts), and avoidance (e.g., not visiting certain areas because of preconceived fears, stories they heard from elders, stories they read in the popular media).

Where discrimination surfaced for informants participating in the Delphi phase centered on inequity of national park facilities and opportunities (e.g., not accommodating extended families or neighborhood groups), perception by ethnic minorities that the national parks are an "exclusive club" for middle-upper class white people and "are not welcoming" to minorities. Other common themes for this category pertained to hiring procedures, 
park programs, and interpretive efforts geared to the mainstream, traditional audiences.

Furthermore, the structural constraint of institutional racism is a powerful, very real, and largely documented problem among Native American communities in anthropology and ethnographic studies (Pickering, 2000a), yet scholars in parks and recreation continue to evade this issue with Blacks and Latinos calling it "perceived discrimination." The constraint dimension, for example, of "culture of the NPS" received multiple comments as one of the greatest barriers to visiting RMNP more often or at all. The underlying strength of racism as a potentially very real issue should not be overlooked, rather addressed head on. The NPS has made a variety of concerted efforts at educating employees internally about the "need" for outreach; special programs and initiatives have occurred in some areas, and a few collaborative management efforts have only just begun (e.g., Interagency collaboration with Golden Gate National Recreation Area, Crissy Field Center, and the Presidio Trust).

Ethnic minority communities, however, from the local resident (e.g., "lay person") up to community leaders and professionals continue to express lack of connection - not to the land, special places, and spectacular natural beauty, but a disconnect from how the Park Service manages these areas and conducts their business. This needs to change if attitudes towards the NPS will change. Results of this study suggest the need for the NPS to help mitigate the constraining forces and encourage more broad-based, integrative approaches to enhancing outdoor recreation and improving natural resources education.

\section{Conclusions}

Research on this topic is both simple and complex. The easy elements revolve around the notion that America's national parks are for all people while the intricacy weaves around misunderstandings and challenges of ethnic and cultural diversity. This study consisted of a small sample yet because of the qualitative paradigms used, it contains rich responses and realizations. While the literature is somewhat inconsistent, it has established important cornerstones 


\section{Ethnic Studies Review Volume 31}

for exploring the subject of ethnic minority recreation in national parks.

This present study identified and explored visitor use and nonuse by ethnic minorities residing along the Front Range of Colorado (from Fort Collins to Denver) as well as engaged a national panel of Black and Latino professionals in natural resource management and related fields. Especially given the small proportion of ethnic minorities in the study area, this provides Rocky Mountain National Park with a well-informed sense of constraints to visiting the park. By understanding the results of this research, RMNP managers should determine what they can do in assisting with breaking down existing barriers; this includes implementing innovative outreach strategies while attempts are made to prevent further hurdles from occurring.

Regarding the theoretical frameworks, constraints research in recreation and parks has expanded in scope and gained sophistication over the last twenty years as a distinct "subfield of leisure studies" (Jackson, 1991). Since this was noted by Jackson more than sixteen years ago, the efforts to advance the general theory of constraints by incorporating the lessons learned from studying the recreational behavior of ethnic minorities have been limited. Discrimination will continue to be a critical component in furthering our understanding of underserved populations. The notion of discriminatory practices on public lands is a particularly volatile topic that researchers might be reluctant to address. Perhaps this is why discrimination in parks and recreation must remain in the forefront of theoretical frameworks in future research.

In part, as aptly noted by Marks (1993) and indisputably related to the results of the present study "it is impossible to 'prove' the presence or absence of discrimination" (p. 160, in Stanfield \& Dennis). Furthermore, not all inequality is the result of discrimination, and not all discrimination results in inequality. Knowing the difference can mean a great deal for advancing the state of the art in research on race, ethnicity and culture in outdoor recreation. Additionally, and also noted by Marks, discrimination is not measured directly but is the residual (or net difference) between majority-minority attainment after other factors are held 


\section{Roberts-Use of Multiple Methods}

constant (Marks, in Stanfield \& Dennis, 1993).

For ethnic minorities, their experiences with discrimination around parks may not necessarily be any different from their experiences in life. Even if there are no discriminatory acts, people often expect something to occur because they may face certain circumstances daily or their perceptions of what might happen are enhanced.

Second, key inferences can be made about the methodological implications of this study. The use of a mixed-method approach accentuates how obtaining such an assortment of data can assist land managers in gaining a much better viewpoint of the issues relating to ethnic minority use of parks. Use of two qualitative techniques greatly enhanced the overall value and contribution to the field as well as the general outcomes of this study. The qualitative methods of focus group interviews and engaging a panel of experts via the Delphi technique allowed for obtaining depth of information, expression of attitudes, exploration of feelings, drawing out opinions, listening to stories about experiences, acquiring profound release of thoughts, and an all around wealth of "data" with multiple layers. The results are manifest in the robust material examined and quantity of all transcripts completed. Caution should be noted, however, in that the findings from this study cannot be generalized so inferences cannot be made about some characteristic, attitude, or behavior of this population (Creswell, 2003).

Few studies employ mixed-methodology for pragmatic reasons, yet we feel combining two qualitative phases of the data in this study was a necessary and appropriate undertaking. This was based on the assumption that any bias inherent in particular data sources and methods would be neutralized when used in conjunction with other data sources and methods. Overall, combining the data added scope and breadth to this study, and provided refreshing and adequate judgments of inquiry. Use of mixed-methods to study ethnic minority populations may continue to be essential in the future for the parks and recreation field as well as other disciplines. 


\section{Ethnic Studies Review Volume 31}

\section{Suggestions for Future Research}

Many suggestions can be made regarding current gaps and recommendations for future research. One concept relates to the process of "negotiation." For example, in their synthesis of research, Jackson and Scott (1999) note that participants may be equally constrained as non-participants. They note that these groups are set apart by the fact participants have somehow found the course of action to address, alleviate, or even overcome their constraints (i.e., "negotiation"). How preferences and participation are linked in the negotiation process is not very well known. The problem with constraint negotiation is that the burden is almost always on individuals; societal issues must be addressed as well (Henderson, et al., 1996). Antecedent constraints (e.g., societal) such as gender expectations, familial support, and media messages are examples of social constraints that are difficult for an individual to overcome and have received little attention (Martin, 2004).

Sasidharan (2002) discusses the need to understand how race and ethnicity interact with other cultural variables (e.g., gender, age, religion) to influence outdoor recreation preferences. He concludes by pointing out the need to analyze cultural components (e.g., race and ethnicity, age and cohort, and gender) with "social roles, group relations, and inequality among other social structural variables" in order to increase overall understanding of leisure behavior (p. 8).

Furthermore, Rodriguez and Roberts (2002) found that much of the literature they reviewed examined race/ethnicity, gender, and social class in relation to outdoor recreation and parks visitation and that these variables have been studied either independently or in pairs (e.g., race and class, gender and ethnicity). Few studies, on the other hand, included the full combination of all variables and their association to participation in outdoor recreation activities. The gaps found were determinants that more research is needed on concepts of avoidance and displacement, people with disabilities, the elderly, motivation, user conflicts, and meaning/ place attachment which made up, collectively, only $10 \%$ of the literature reviewed.

A recent study consisted of a content analysis of advertisements from three magazines (i.e., Time, Outside, and Ebony) over a sixteen 


\section{Roberts-Use of Multiple Methods}

year period between 1984 and 2000. Advertisements taking place in the "great outdoors" or featuring models participating in wilderness activities rarely included Black models, while White people who frequent outdoor settings and activities were featured regularly in the ads. Within the pages of the magazine advertisements reviewed, Black models were limited to urban and suburban environments while results showed Whites had exclusive domain over the "great outdoors". Findings of this study have potential consequences for how Blacks and Whites perceive wilderness recreation and wilderness spaces. Additionally, this also symbolized a need for ethnic media sources to consider the implications and potential new avenues (Roberts, 2007).

One example reflecting the growing need to understand the influence of ethnic media on communicating with diverse communities was a study conducted by Winter, Jeong, and Godbey (2004). Asian Americans in the Bay Area were surveyed to understand perceived constraints to visiting the Golden Gate National Recreation Area. Among their numerous findings, results show this population indicated a heavy emphasis on utilizing ethnic media as important sources of information. This is also known to be essential in other racial and ethnic communities, including Blacks and Latinos (New America Media, 2007). In general, these (and other studies) indicates there is a dearth of research in this area of media representation relating to the field of outdoor recreation and parks management and illustrates a future need as well.

\section{Closing thoughts}

National Parks have really always been, and always will be, cultural icons. The management structure, political pressures, and heavy historical military influence have contributed to the current perceptions of these special places and often activities that may occur there as "a white thing." Enormous efforts have taken place over the years by the NPS to welcome diversity and be more inclusive. Many parks have embraced the challenge of reaching out to diverse audiences through creative approaches such as hiring bilingual community liaisons, hosting unique cultural events (Posada processionals, Pow-wow's, etc), and inclusive interpretive 


\section{Ethnic Studies Review Volume 31}

programs and messages such as telling the story of the Buffalo Soldiers (Rodriguez \& Roberts, 2002). Parks across the country also have organized community programs and funding for transportation, multi-day experiences for inner-city school children, and intentional hires of bilingual staff at all levels. There is incredible hope for all people across cultures to experience the spectacular landscapes of our national parks and embrace the educational and recreational opportunities that abound. This can be achieved in a way that is comfortable, safe, rewarding, and empowering, to name a few.

Now is the time for the vision of the American dream we have for our parks to become real. We need to fulfill a vision of the dream for our national parks in which we are liberated from the politics of ethnicity/race to openly embrace any style, cultural dialogue, or image of parks as special places to all of us in some capacity regardless of what that might be. Learning about the attitudes, perceptions, and experiences of different ethnic and cultural groups has huge merit; this fact is indisputable and warrants new directions.

Ensuring relevance is going to be the key to success. For example, education, increasing knowledge, providing exposure for youth, bringing "parks to the people", and being visible in various forms of ethnic media. One of many ways of accomplishing this is for national park managers and other public land agency personnel to find ways to connect with journalists of ethnic media sources when promoting newsworthy events, stories, and park-related functions, and celebrations.

As reflected in this study, this means there is still a need to understand these facets about ethnic minorities to ensure or enhance their national park experience. Finally, the National Park Service must continue adjusting to the "changing demographics" reality because this is a trend that will only accelerate.

Authors Note and Acknowledgements: This study was based on doctoral research completed by Nina Roberts at Colorado State University. Funding was provided by Rocky Mountain National Park, U.S. National Park Service. 


\section{Roberts-Use of Multiple Methods}

\section{References}

Allison, M.T. (1988). Breaking boundaries and barriers: Future directions in cross-cultural research. Leisure Sciences, 10, 247259.

Anderson, D.H. \& Schneider, I.E. (1993). Using the Delphi process to identify significant recreation research-based innovations. Journal of Park and Recreation Administration, 11(1), 25-36.

Arnold, M. L., \& Shinew, K. J. (1998). The role of gender, race, and income on park use constraints. Journal of Park and Recreation Administration, 16(4), 39-56.

Baughman, M.J. (1985). Effective use of the Delphi process. In R.A. Leary (Ed.), Discovering new knowledge about trees and forests (US Forest Service GTR No. NC-135, pp. 69-76). St. Paul, MN: North Central Forest Experiment Station.

Clark, R.N. \& Stankey, G.H. (1991). New forestry or new perspectives? The importance of asking the right questions, Forest Perspectives, 1(1), 9-13.

Comas-Diaz, L. (2001). Hispanics, Latinos or Americanos: The evolution of identities. Cultural diversity and ethnic minority populations, 7(2), 115-120.

Crawford, D.W., Jackson, E.L., \& Godbey, G. (1991). A hierarchical model of leisure constraints. Leisure Sciences, 13, 309-320.

Creswell, J.W. (2003). Research design: Qualitative, Quantitative, and Mixed Method Approaches, $2^{\text {nd }}$ ed. Thousand Oaks, CA: SAGE.

Dwyer, J.F. (1994). Customer diversity and the future demand for outdoor recreation. General Technical Report RM-252. Fort Collins, CO: U.S. Department of Agriculture, Forest Service, Rocky Mountain Forest and Range Experiment Station. 


\section{Ethnic Studies Review Volume 31}

Floyd, M.F. (2001). Managing national parks in a multicultural society: Searching for common ground. George Wright Forum, (18)3, 41-51.

Floyd, M.F. (1999). Race, ethnicity and use of the National Park System. National Park Service, 1: 1-24. Washington, DC: Department of the Interior.

Gobster, P.H. (Ed.). (1993). Managing Urban and High-Use Recreation Settings. North American Symposium on Society and Resource Management GTR, NC-163. Madison, WI: University of Wisconsin: USDA Forest Service, North Central Forest Experiment Station.

Gómez, E. (2007). Race, Ethnicity, Recreation, and Leisure: An Assessment of Research Gaps. Unpublished report provided to the USDA Forest Service, Pacific Southwest Research Station. $14 \mathrm{p}$.

Gómez, E. (2003). Ethnicity and recreation; An abridged annotated bibliography. Unpublished report provided to the USDA Forest Service, Pacific Southwest Research Station. 57p.

Gramann, J.H. \& Allison, M.T. (1999). Ethnicity, race and leisure. In E.L. Jackson \& T.L. Burton (Eds.), Leisure Studies: Prospects for the Twenty-First century. State College, PA: Venture.

Gramann, J. H. (1996). Ethnicity, race, and outdoor recreation: A review of trends, policy, and research (Miscellaneous Paper R-96-1). Vicksburg, MS: U.S. Army Engineer Waterways Experiment Station.

Hartmann, L. A. \& Overdevest, C. (1989). Race, ethnicity, and outdoor recreation participation: A state-of-the-knowledge review and theoretical perspective. In K. Zera (Ed.), Southeastern Recreation Research Conference (pp. 53-63), Athens, GA: Institute for Behavioral Research, U.S. Forest Service. 
Henderson, K.A. Bialeschki, M.D., Shaw, S.M. \& Freysinger, V.J. (1996). Both gains and gaps. State College, PA: Venture.

Henderson, K.A. \& Bialeschki, M.D. (1993). Exploring an expanded model of women's leisure. Journal of Applied Recreation Research, 18(4), 229-252.

Hutchison, R. (2000). Race and ethnicity in leisure studies. In W.C. Gartner and D.W. Lime (Eds.), Trends in Outdoor Recreation, Leisure and Tourism. Cambridge, MA: CAB International.

Jackson, E.L. (Ed.)(2005). Constraints to leisure. State College, PA: Venture.

Jackson, E.L. \& Scott, D. (1999). Constraints to leisure. In E.L. Jackson \& T.L. Burton (Eds.), Leisure studies: Prospects for the Twenty-First century, pp. 299-321. State College, PA: Venture.

Jackson, E.L. \& Henderson, K.A. (1995). Gender-based analysis of leisure constraints. Leisure Sciences, 17, 31-51.

Johnson, C. Y., Bowker, J.M., Cordell, K. (2001). Outdoor recreation constraints: An examination of race, gender, and rural dwelling. Southern Rural Sociology, 17, 111-133.

Johnson, C.Y. Bowker, J.M., English, D.B.K., Worthen, D. (1997). Theoretical perspectives of ethnicity and outdoor recreation: A review and synthesis of African and European-American participation. USDA Forest Service, Southern Research Station, GTR-SRS 11, 1-16.

Jones, R.E. (1998). Black concern for the environment: Myth versus reality. Society and natural resources, 11, 209-228.

Machlis, G.E. \& Field, D.E. (2000). National parks and rural development: Practice and policy in the United States. 


\section{Ethnic Studies Review Volume 31}

Washington, DC: Island Press.

Marks, C.C. (1993). Demography and race. In, J.H. Stanfield and R.M. Dennis (Eds.), Race and ethnicity in research methods, pp. 159-171. Newbury Park, CA: SAGE.

Martin, D. (2004). Apartheid in the great outdoors: American advertising and the reproduction of a racialized outdoor leisure identity. Journal of Leisure Research, 36(4), 513-535.

New America Media (2007). Expanding the news lens through ethnic media. Retrieved June 3, 2007, from the World Wide Web, http://news.newamericamedia.org/news.

Parker, J.D. \& McDonough (1999). Environmentalism of African Americans: An analysis of the subculture and barrier theories. Environment and Behavior, 31(2), 155-177.

Parry, D., Shinew, K.J, Arnold, M. (2001). Broadening the understanding of race and constraint. Paper presented at the NRPA Leisure Research Symposium. Denver, CO.

Philipp, S.F. (1995). Race and leisure constraints. Leisure Sciences, $17,109-120$.

Pickering, K.A. (2000a). Lakota culture, World economy. Lincoln, NE: University of Nebraska Press.

Pickering, K.A. (2000b). Alternative economic strategies in lowincome rural communities: TANF, labor migration, and the case of the Pine Ridge Indian Reservation. Rural Sociology, 65(1), 148-167.

Richey, J.S., Mar, B.W. \& Horner, R.R. (1985). The Delphi technique in environmental assessment: Implementation and effectiveness, Journal of Environmental Management, 21, 135-146.

Roberts, N.S. (2007). "Visitor/Non-Visitor Use Constraints: 
Roberts-Use of Multiple Methods

Exploring Ethnic Minority Experiences and Perspectives." General Technical Report, Golden Gate National Recreation Area, National Park Service. San Francisco, CA: San Francisco State University.

Rodriguez, D.A. \& Roberts, N.S. (2002). "State of the Knowledge Report: The association of race/ethnicity, gender, and social class in outdoor recreation experiences." National Park Service, Social Science Program, General Technical Report, Colorado State University at Fort Collins.

Samdahl, D.M. \& Jekubovich, N.J. (1997). A critique of leisure constraints: Comparative analyses and understandings. Journal of Leisure Research, 29(4), 430-452.

Sasidharan, V. (2002). Special issue introduction: Understanding recreation \& the environment within the context of culture. Leisure Sciences, 24, 1-11.

Schelhas, J. (2002). Race, ethnicity, and natural resources in the United States: A review. Natural Resources Journal, 42, 723-763.

Shinew, K.J., Stodolska, M., Floyd, M., Hibbler, D., Allison, M., Johnson, C., Santos, C. (2006). Race and ethnicity in leisure behavior: Where have we been and where do we need to go? Leisure Sciences, 28, 403-408.

Shinew, K.J., Floyd, M.F. \& Parry, D. (2004). Understanding the relationship between race and leisure activities and constraints: Exploring an alternative framework. Leisure Sciences, 26, 181199.

Shores, K.A., Scott, D., Floyd, M.F. (2007). Constraints to outdoor recreation: A multiple hierarchy stratification perspective. Leisure Sciences, 29, 227-246.

Solop, F.I., Hagen, K.K., \& Ostergren, D.(2003). "Ethnic and Racial Diversity of National Park System Visitors and Non-Visitors." 


\section{Ethnic Studies Review Volume 31}

Technical Report submitted to the U.S. National Park Service Social Science Program. Social Research Laboratory, Northern Arizona University.

Stanfield, J.H. \& Dennis, R.M. (1993). Race and ethnicity in research methods. Newbury Park, CA: SAGE.

U.S. Census Bureau (2004). Race and Hispanic or Latino origin. Retrieved February 15, 2004, from http://www.census.gov/

Virden, R. J. \& Walker, G.J. (1999). Ethnic/racial and gender variations among meanings given to, and preferences for, the natural environment. Leisure Sciences, 21, 219-239.

Walker, G. J., Jackson, E.L., \& Deng, J. (2005). Culture and leisure constraints: A comparison of Canadian and Mainland Chinese students. National Recreation and Park Association Book of Abstracts for 2005 Leisure Research Symposium (LRS), National Park and Recreation Congress. San Antonio, TX.

Weatherman, R. \& Swenson, K. (1974). Delphi technique. In S.P. Hencley \& J.R. Yates (Eds.), Futurism in Education: Methodologies (pp. 97-114). Berkeley, CA: McCutchen.

West, P. C. (1989). Urban region parks and black minorities: Subculture, marginality, and inter-racial relations in park use in the Detroit metropolitan area. Leisure Sciences, 11, 11-28.

Williams, D.R. \& Carr, D.S. (1993). The sociocultural meanings of outdoor recreation places. In A.W. Ewert, D.J. Chavez, \& A.W. Magill (Eds.), Culture, conflict, and communication in the wildland-urban interface, pp. 209-219. Boulder, CO: Westview Press.

Winter, P.L., Jeong, W.C., \& Godbey, G.C. (2004). Outdoor recreation among Asian Americans: A case study of San Francisco Bay Area residents. Journal of Park and Recreation Administration, 22 (3), 114-136. 